\title{
Is Age of Onset of Crohn's Disease Governed by Mutations in NOD2/Caspase Recruitment Domains 15 and Toll-Like Receptor 4? Evaluation of a Pediatric Cohort
}

\author{
ESTHER LESHINSKY-SILVER, AMIR KARBAN, ERENA BUZHAKOR, MARCELO FRIDLANDER, \\ BENJAMIN YAKIR, RAMI ELIAKIM, SHIMON REIF, RONI SHAUL, MONA BOAZ, \\ DORIT LEV, AND ARIE LEVINE \\ Molecular Genetics Laboratory [E.L.-S., E.B.], Department of Epidemiology [M.B.], Genetics Institute [D.L.], \\ and Pediatric Gastroenterology Unit [A.L.], the E. Wolfson Medical Center Holon, Holon, Israel, 58100; \\ Division of Gastroenterology [A.K., R.E.], Rambam Medical Center Haifa, Haifa, Israel, 31096; Danyel \\ Biotech [M.F.], Science Park, Rehovet, Israel, 78124; Department of Statistics [B.Y.], the Hebrew University of \\ Jerusalem, Jerusalem, Israel, 90000; Pediatric Gastroenterology Unit [S.R.], Dana Children's Hospital, \\ Tel Aviv, Israel, 64239; Pediatric Gastroenterology [R.S.], Bnei Zion Medical Center, Haifa, Israel, 31048; and \\ Tel Aviv University Sackler School of Medicine [A.L.], Tel Aviv, Israel, 60000
}

\section{ABSTRACT}

Crohn's disease (CD) is caused by a combination of environmental and genetic factors. It is not clear at present whether age of onset (AOO) is a random event or dictated by genotype or environmental factors. Mutations in the NOD2/caspase recruitment domains 15 (CARD15) and in the Toll-like receptor 4 (TLR4) gene have been associated with increased susceptibility for $\mathrm{CD}$. We sought to determine whether single or multiple mutations in these genes are linked to earlier susceptibility for CD. A cohort of 189 patients with CD (82 pediatric onset, 107 adult onset) were genotyped for three disease-associated singlenucleotide polymorphisms (SNPs), one haplotype association (JW1-SNP5), and one background polymorphism (P268S) of the NOD2/CARD15 gene and for two SNPs of TLR4. Analysis of heterozygosity, homozygosity, alleles, and haplotypes of cohort on age or pediatric onset was performed. AOO ranged from $8 \mathrm{mo}$ to $68 \mathrm{y}$. The presence of the three NOD2/CARD15 and two TLR4 mutations, the NOD2/CARD15 JW haplotype, compound heterozygosity, and homozygosity were not associated with AOO. Presence of P268S in the absence of known NOD2/
CARD15 mutations was correlated with increasing age and adult onset of $\mathrm{CD}$, whereas pediatric-onset disease was associated with male gender and the wild-type NOD2/CARD15 haplotype. Mutations in NOD2/CARD15 and TLR4 are not significantly associated with AOO in our population. Mutations that are not in linkage disequilibrium with the background mutation P268S of the NOD2/CARD15 gene probably play a more significant role in pediatric-onset disease. (Pediatr Res 58: 499-504, 2005)
AOO, age of onset
Abbreviations
CARD, caspase recruitment domain
CD, Crohn's disease
IBD, inflammatory bowel disease
LLR, leucine-rich repeat
LPS, lipopolysaccharide
SNP, single-nucleotide polymorphism
TLR4, Toll-like receptor 4

Crohn's disease $(\mathrm{CD})$ is thought to result from combined effects of environmental agents and a genetically susceptible host. A central role for the innate immune responses to discrete antigens has been postulated. A perturbation in the immune response to luminal bacteria leads to inflammation

Received August 16, 2004; accepted January 4, 2005.

Correspondence: Esther Leshinsky-Silver, Ph.D., Molecular Genetics Lab, E. Wolfson Medical Center, POB 5, Holon, Israel, 58100; e-mail: leshsil2@inter.net.il or leshinsky@wolfson.health.gov.il.

DOI: 10.1203/01.PDR.0000175640.75468.D6 in the gastrointestinal tract (1-4). The disease can affect both children and adults. Early presentation of the disease in the first decades of life carries significant morbidity and mortality (5-7). A high risk for complications associated with early onset of the disease is thought to reflect longer lifetime duration of disease and medication use, effects of the disease during periods of growth and development, and possibly a more severe phenotype of the disease as a result of a specific genotype-causing predisposition to early onset of the disease. 
The first susceptibility gene that has been identified in patients with $\mathrm{CD}$ is the NOD2/caspase recruitment domains 15 (CARD15) gene on chromosome 16 (8-12). NOD2/CARD15 is a protein composed of $2 \mathrm{~N}$-terminal CARD, a nucleotidebinding domain, and C-terminal leucine-rich repeats (LLRs). Functional studies have shown that NOD2/CARD15 confers responsiveness to bacterial peptidoglycans through LLRs. It has been suggested that NOD2/CARD15 activates the nuclear factor- $\kappa \mathrm{B}$ pathway in response to bacterial luminal exposure through the specific recognition of bacterial muramyl dipeptides (13-15).

Three main mutations (R 702W, G908 R, and 1007 frameshift) have been described in $\mathrm{CD}$ and have been linked to the phenotype of the disease $(8-10)$, whereas other studies have not found such a correlation (16-18). Carriage of single nucleotide polymorphisms (SNPS) in the NOD2/CARD15 gene has been linked to ileal disease. A haplotype association was linked to development of CD in the Ashkenazi Jewish population (P268S and JW1), although this is controversial $(19,20)$. Recently, five novel changes in the NOD2 gene were revealed, one of which occurred only in Ashkenazi Jews (20). These have not been evaluated in childhood-onset disease.

Genetic susceptibility, leading to early presentation of the disease, theoretically could be due to the type of mutation or to a combination of mutations in the same or different genes. Studies involving the three early NOD2/CARD15 mutations in fact found earlier adult onset with compound heterozygotes, although this was associated with familial disease. However, the three early mutations in NOD2/CARD15 do not account for the majority of patients and led to a mean onset that was only 3 y younger $(16,21)$. Another study found that NOD2/CARD15 mutations confer an odds ratio for early onset that was borderline at best (22).

The human Toll-like receptors are a type I transmembrane protein with an extracellular domain consisting of a LLR region and an intracellular domain homologous to that of the human IL-1 receptor (23). Toll-like receptor 4 (TLR4) seems to be the major receptor for lipopolysaccharide (LPS) isolated from most bacterial organisms (24). Downstream, LPSinduced signaling through TLRs rapidly leads to nuclear factor- $\kappa \mathrm{B}$ activation and cytokine expression in monocytes (23).

Recent studies suggest that the overlying epithelial mucous surface may be severely impaired in patients with inflammatory bowel disease (IBD). Moreover, in active ulcerative colitis (UC) and CD, TLR4 was strongly up-regulated, whereas TLR2 and TLR5 remained unchanged (25). This shows a selective TLR expression in intestinal epithelium, suggesting that alternation in the response system contributes to the pathogenesis of the disease.
Two common co-segregating missense mutations were described in TLR4 gene: Thr399Ile and Asp299Gly, affecting the extracellular domain of the TLR4 receptor and associated with a blunted response to inhaled LPS in humans (specifically the Asp299Gly) (26). The relatively high frequency of these mutations in the white population may reflect modified responses of carriers to alternative TLR4 agonists (27). Spontaneous IBD-like disease occurs in mice with mutations in the TLR4 gene $(28,29)$. Recently, an association between the Asp299Gly mutation and $\mathrm{CD}$ was described, strengthening a possible link between mutations in TLR4 and susceptibility to CD (30). The aim of this study was to elucidate the role of mutations in the NOD2/CARD15 and TLR4 genes in pediatric CD cohort and to find a possible age-related phenotype-genotype correlation in an attempt to explain the diversity in age of onset (AOO) of CD.

\section{METHODS}

Study population. Patients were eligible when CD was confirmed by established criteria on the basis of clinical, radiologic, endoscopic, and histopathologic findings. Radiologic criteria included strictures or cobblestone pattern or linear ulcerations on a barium swallow with small bowel followthrough. All patients in the study had both a radiologic and an endoscopic work-up with biopsies. Patients with IBD-like disease in the presence of a known immune deficiency state, such as glycogen storage disease or chronic granulomatous disease, were excluded. The study consisted of two consecutively recruited cohorts of single-family members, through four pediatric gastroenterology and two adult gastroenterology programs distributed throughout central and northern Israel. The first cohort included patients with clinical onset of disease $<18 \mathrm{y}$ of age (pediatric cohort), and the second cohort included patients with clinical onset $\geq 18$ y of age. The Wolfson Medical Center Review Board and the Israel Ministry of Health Genetic Research Review Board approved the recruitment protocol. Informed consent was obtained from all parents and patients. Data regarding the AOO and family history was obtained from the patients and the referring gastroenterologist and registered before genotyping. All genotyping was performed by a single investigator who was blinded to phenotypic data (E.L.-S.). The control group consisted of 159 healthy control subjects analyzed by our centers and previously described (31).

Genetic analysis. Genomic DNA was extracted from whole peripheral venous blood, using a commercially available kit (Gentra, Minneapolis, MN) in accordance with the manufacturer's instructions. The NOD2 mutations were analyzed by the Pyrosequencing technology (32). PCR was performed with the corresponding oligonucleotides to amplify the desired DNA fragment (Table 1). SNP was analyzed with a PSQ sample preparation kit from Pyrosequencing AB (Uppsala, Sweden). Analysis of the various SNPs was performed on a PSQ 96MA pyrosequencer, using $0.2-\mu \mathrm{M}$ sequencing primers according to standard protocols. The order of nucleotide dispensation was decided on the basis of suggestions provided by the PSQ HS 96 SNP software 1.0 (Pyrosequencing $\mathrm{AB}$ ), which was also used for automatic assay evaluation and genotype scoring.

The two mutations of the TLR4 gene (Asp299Gly and Thr399Ili) were analyzed by PCR amplification using mismatched primers to generate a restriction site in the mutant allele according to Lorenz et al. (33). Briefly, for the Asp299Gly mutation, the following primers were used: forward primer 5'-GATTAGCATACTTAGACTACTACCTCCATG-3' and reverse primer 5'GATCAACTTCTGAAAAAGCATTCCCAC-3'. For the Thr399lle, forward primer 5'-GGTTGCTGTTCTCAAAGTGATTTTGGGAGAA-3' and reverse

Table 1. Primers used for NOD2 genotyping by the pyrosequencing method

\begin{tabular}{llllc}
\hline SNP & \multicolumn{1}{c}{ Primer forward } & \multicolumn{1}{c}{ Primer reverse } & \multicolumn{1}{c}{ Sequence primer } \\
\hline P268S & Biotin-ACACAGAGAATGTCCTGGAGGT & AGCTGAATGGGAAGACAAGAG & GGCTCTTCTGCGGG \\
R702W & CACAACCTTCAGATCACAGCAG & Biotin- & TCTGAGAAGGCCCTG & 244 \\
& & GGATGGAGTGGAAGTGCTTG & & \\
G908R & cactgtctgttgactctttg & Biotin cctgatctccccaagaaaactg & gcctttcagATTCTGG & 165 \\
1007fs & Biotin-atctttttccagGTTGTCCA & gatcctcaaaattctgccattc & TTCCTTTCAAGGG & 160 \\
JW1 & ctacccacaatgttaggcaat & Biotin-atttcaagtcacccagaaga & gatttcaagagaggacact & 198 \\
\hline
\end{tabular}


Table 2. Entry data and presence of single or multiple NOD2 and TLR4 mutations

\begin{tabular}{lccc}
\hline \multicolumn{1}{c}{ Parameter } & $\begin{array}{c}\text { Group 1 } \\
(n=82)\end{array}$ & $\begin{array}{c}\text { Group 2 } \\
(n=107)\end{array}$ & $\begin{array}{c}\text { Total } \\
(n=189)\end{array}$ \\
\hline Age & 12.8 & 30.0 & $22.3 \pm 12.6$ \\
$\%$ male* & $* 64 \%$ & $* 49 \%$ & $56 \%$ \\
Double NOD2 & $8.5 \%$ & $8.4 \%$ & $8.4 \%$ \\
Any NOD2 & $31.7 \%$ & $37.4 \%$ & $35 \%$ \\
No NOD2 & $68.3 \%$ & $62.6 \%$ & $65 \%$ \\
Any TLR4 & $10.6 \%$ & $10.3 \%$ & $10.4 \%$ \\
No TLR4 & $89.4 \%$ & $89.7 \%$ & $89.6 \%$ \\
\hline
\end{tabular}

$* p<0.05$.

primer 5'-ACCTGAAGACTGGAGAGTGAGTTAAATGCT-3' were used PCR was performed in a $50-\mu \mathrm{L}$ volume that contained $10 \mathrm{mM}$ Tris- $\mathrm{HCl}(\mathrm{pH}$ 8.3), $50 \mathrm{mM} \mathrm{KCl}, 1.5 \mathrm{mM} \mathrm{MgCl} 2,250 \mu \mathrm{M}$ dNTPs, $1 \mu \mathrm{M}$ of each primer, 200 ng of genomic DNA, and 1.25 U of AmpliTaq Gold DNA polymerase (Perkin Elmer Applied Biosystem, Roche Diagnostic System, Alameda, CA) with an initial denaturation step of $10 \mathrm{~min}$ at $95^{\circ} \mathrm{C}$ to activate the polymerase followed by 35 cycles of $94^{\circ} \mathrm{C}$ for $15 \mathrm{~s}, 55^{\circ} \mathrm{C}$ for $45 \mathrm{~s}, 72^{\circ} \mathrm{C}$ for $45 \mathrm{~s}$, and a final extension at $72^{\circ} \mathrm{C}$ for $10 \mathrm{~min}$. Predicted sizes were confirmed by agarose gel electrophoresis. PCR product was digested overnight with $N c o$ I (for the Asp299Gly mutation) and HinfI (for the Thr399Ile mutation). Digests were run on a 3\% Nusieve agarose to determine the TLR4 alleles.

Statistics. The statistical analysis was conducted with the $\mathrm{R}$ statistical programming environment (http://cran.r-project.org). AOO was treated as a continuous response. In the genotype test (Table 2), the genotypes of each of the SNPs was entered as a three-level factor in an ANOVA test via the application of the aov function. A linear regression was used for testing the additive effect of the mutated alleles. The number of mutated alleles served as an explanatory variable, and the significance of the slope was tested using the $t$ test (implemented by the $l m$ function). All analyses were corrected for an additive gender-by-origin effect. For that sake, we introduced a factor that identifies all male individuals who are either Ashkenazi or of mixed origin. It should be noted that this covariate turned out to be the most significant in all analyses. However, it had only a small effect on the significance of the genetic covariates.

Associations between haplotypes and the AOO were examined with the haplo.score function. The most frequent haplotypes involving each gene are presented in Table 3. This function examines the additive effect of haplotype alleles and is parallel to the investigation of the additive effect of alleles of a single SNP. We used the options trait.type = "gaussian" and skip.haplo = 0.05 . The analysis was adjusted for an Ashkenazi-male effect. The perhaplotype $p$ values and the $p$ value of the most significant haplotype (corrected for the multiple testing over all haplotypes) were computer based on 10,000 simulations. The study has $85 \%$ power to detect a $4.4-y$ difference in age for the presence of a mutation.

\section{RESULTS}

Population data. Data were obtained from 189 patients. There were 82 patients in the early-onset cohort (mean age of onset $12.77 \pm 4.48$; range 8 mo to $18 \mathrm{y}$ ) and 107 patients in the adult-onset cohort (mean age of onset $29.98 \pm 12.29$; range $19-68$ y). Our population consisted of $96 \%$ Jews and $4 \%$ non-Jews. Nearly $51 \%$ of our cohort was of pure JewishAshkenazi decent, 33\% were of Jewish-Sephardic decent, $12 \%$ were of a mixed Ashkenazi-Sephardic decent, and $4 \%$ were non-Jewish white individuals. No association was found between ethnicity and AOO $(p=0.61)$, and there was no difference in ethnic breakdown between age groups. Data regarding age, gender, and NOD2 carriage are presented in Table 2.

There were 106 men and 83 women. Mean age for men was $20.7 \pm 1.0$ versus $24.7 \pm 1.7$ y for women $(p=0.032)$. Men tended to be younger when they were of Ashkenazi or mixed origin, in comparison with Sephardic origin. The mean age for
Table 3. Association among NOD2, TLR4 haplotypes, and CD $A O O$

\begin{tabular}{lccc}
\hline & $\begin{array}{c}\text { Frequency } \\
(\%)\end{array}$ & $\begin{array}{c}\text { Additive } \\
\text { effect }\end{array}$ & $p$ value \\
\hline Frequent NOD2 haplotypes: all SNPs & & & \\
$8-12-13-J W 1-5^{*}$ & & & \\
$1-1-1-1-1$ & 59.2 & -1.81 & 0.07 \\
$1-1-2-2-2$ & 5.7 & -0.56 & NS \\
$1-1-1-2-2$ & 8.9 & -0.67 & NS \\
1-2-1-1-2 & 10.8 & 1.52 & NS \\
1-1-1-1-2 & 9.2 & 2.55 & $0.011(0.05)$ \\
Frequent TLR4 haplotypes: all SNPs & & & \\
299-399 & & & \\
$1-1$ & 94.24 & NS & NS \\
$1-2$ & 1.4 & NS & NS \\
$2-2$ & 4.67 & NS & NS \\
\hline
\end{tabular}

Additive effect denotes increase in age if result is positive, decrease in age if negative.

O Corrected for multiple testing.

* SNP8 = R702W, SNP12 = G908R, SNP13 = 1007fs, SNP5 = P268S; $1=$ wild type, $2=$ mutated.

Ashkenazi men was $19.3 \pm 1.3$ y versus $22.3 \pm 1.7$ y for Sephardic men and for Ashkenazi women was $23.44 \pm 1.6$ versus $24.9 \pm 2.2$ for Sephardic women. There was a trend for a decrease in the male-to-female ratio as AOO increased. The effect of ethnicity on male gender and AOO is portrayed in Figure 1.

NOD2/CARD15 disease-associated mutations and JW1 haplotype. Disease-associated mutations were found in $35 \%$ of the cohort, in comparison with $10.7 \%$ of a control population. The mutations R702W(SNP8), G908R(SNP12), and 1007FS(SNP13) were found in $18(9.5 \%), 40(21 \%)$, and 21 $(11.1 \%)$ of patients, respectively. The sum of these mutations is higher than the $35 \%$ prevalence rate because of compound heterozygosity.

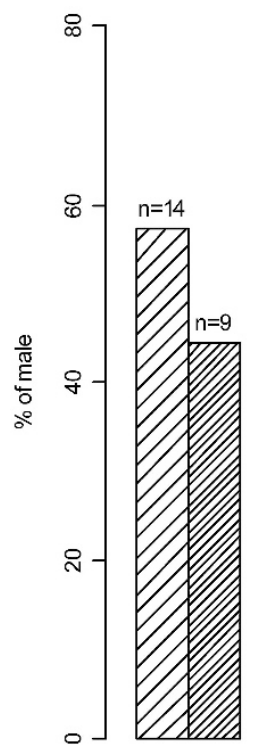

$(0,10]$

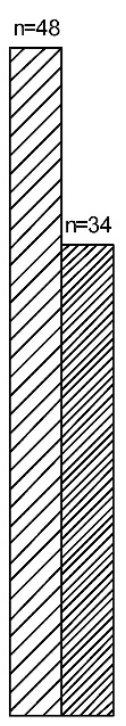

$(10,20]$

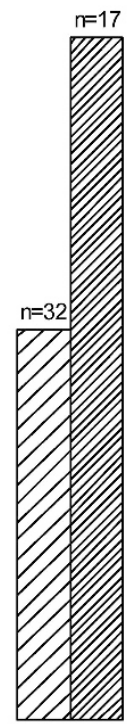

$(20,30]$

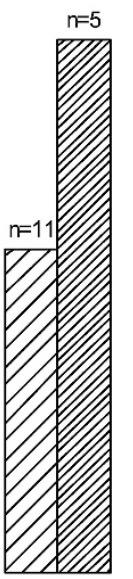

$(30,40]$ $\begin{array}{ll}\square & \text { An Ashk. parent } \\ \square & \text { No Ashk. parent }\end{array}$

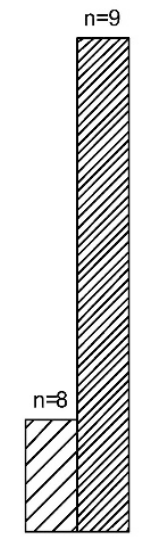

$40+$
Figure 1. Frequency of male individuals within CD-AOO subgroups (by ethnicity). Note that male individuals tend to have earlier AOO when they were of Ashkenazi or mixed origin ( 0,10 and 10,20 columns). 
Table 4. Testing genotypic association between SNPs in NOD2 and TLR4 genes and AOO of CD

\begin{tabular}{|c|c|c|c|c|}
\hline NOD2 SNPs & $\begin{array}{c}\text { Wild-type } \\
\text { [average (SE)] }\end{array}$ & $\begin{array}{l}\text { Heterozygotes } \\
\text { [average } \\
\text { (SE)] }\end{array}$ & $\begin{array}{l}\text { Double dose } \\
\text { [average } \\
\text { (SE)] }\end{array}$ & $p$ value \\
\hline R702W (SNPs) & $22.49(0.98)$ & $23.07(2.58)$ & $13.00(1.53)$ & 0.49 \\
\hline 1007fs (SNP13) & $22.54(0.98)$ & $22.47(2.78)$ & $15.00(3.00) \dagger$ & 0.89 \\
\hline JW1 & $22.84(1.29)$ & $22.21(1.26)$ & $16.43(2.11)$ & 0.66 \\
\hline P268S (SNP5) & $20.87(1.35)$ & $22.71(1.49)$ & $25.34(2.10) \ddagger$ & 0.18 \\
\hline
\end{tabular}

* Only three patients in this group.

$\dagger$ Only two patients in this group.

$\ddagger$ Only one patient in this group.

In the $<10$ y group, NOD2/CARD15 mutations excluding JW1 were found in $27 \%$ of patients. The JW1 haplotype was identified in 26\% of patients, followed by SNP 13 (fs 1007; $17.4 \%$ ) and SNP 12 (R702W; 8.7\%). Only one of six of the patients in the $<5 \mathrm{y}$ of age group had a NOD2/CARD15 mutation.

The effect of genotype by cohort is presented in Table 2, and the effect of homozygosity and compound heterozygosity for NOD2 and TLR4 SNPs on AOO are presented in Table 4. These had no effect on AOO or gender (NS), although the number of homozygotes for R702W and fs1007 in our population was exceedingly small [five patients, $(2.6 \%)$ ]. No homozygotes or compound heterozygotes were found in the control population. The JW1 haplotype was more commonly found than the NOD2/CARD15 mutations but was not associated with $\mathrm{AOO}$ or gender.

The effect of each SNP or the presence of any mutation on mean AOO is presented in Tables 4 and 5. No association was found between alleles that were associated with disease susceptibility and AOO. The distribution of NOD2-positive patients as a percentage of the patient population by decade appears in Figure 2. A trend to older AOO was found for the background polymorphism P268S $(p=0.07)$, which was strengthened by haplotype analysis.

Probabilist haplotype analysis. We included only the most frequent SNPs of the NOD2 gene $(>5 \%)$. The two most common haplotypes that carry the SNP8 mutation in our sample are estimated to have frequencies of $<4 \%$ and $<1 \%$, respectively. Other haplotypes are even rarer. Analysis of haplotypes, presented in Table 3, shows an association between

Table 5. Testing additive association between SNPs in NOD2 and TLR4 genes and CD AOO

\begin{tabular}{lccc}
\hline \multicolumn{1}{c}{ NOD2 SNPs } & $\begin{array}{c}\text { Wild-type } \\
\text { [average (SE)] }\end{array}$ & $\begin{array}{c}\text { Additive effect* } \\
\text { [years (SE)] }\end{array}$ & $p$ value \\
\hline R702W (SNP8) & $24.29(1.12)$ & $-0.78(2.52)$ & 0.76 \\
G908R (SNP12) & $23.81(1.19)$ & $3.03(2.12)$ & 0.15 \\
1007fs (SNP13) & $24.25(1.13)$ & $-0.19(2.59)$ & 0.94 \\
JW1 & $24.69(1.26)$ & $-1.18(1.60)$ & 0.46 \\
P268S (SNP5) & $22.60(1.46)$ & $2.27(1.25)$ & 0.07 \\
Any mutation $\dagger$ & $23.99(1.23)$ & $1.21(1.43)$ & 0.40 \\
Any TLR4 299 or 399 & $22.9(0.96)$ & $-1.3(3.2)$ & 0.7 \\
\hline
\end{tabular}

* Additive effect is in years: positive results indicate increasing age; negative results indicate decreasing age.

$\dagger$ Any mutation refers only to mutated alleles on R702W, G908R, and 1007 fs.
AOO and two haplotypes. The wild-type haplotype (no NOD2associated mutations and no P268S), which occurred in $60 \%$ of patients, showed a tendency for association with pediatric onset $(p<0.07)$. A haplotype characterized by presence of P268S in patients who were naïve for other mutations significantly linked to older AOO $(p=0.01)$. No other haplotype was associated with AOO.

Mutations in TLR4. Mutation analysis was performed in 144 patients (66 with childhood onset and 78 with adult onset in TLR4). Mutations and haplotype analysis are presented in Tables 2-5. TLR4 mutations were not correlated with AOO.

\section{DISCUSSION}

The factors that determine $\mathrm{AOO}$ of $\mathrm{CD}$ are at present unknown. Because presence of multiple alleles of NOD2/ CARD15 seems to have a modest effect on AOO, we hypothesized that an additional hit in a disease-associated gene along the same PRR pathway may contribute to $\operatorname{AOO}(16,22)$. In our study, which compared pediatric-onset with adult-onset disease and probabilist haplotypes versus AOO (independent of an age cutoff), we did not find a correlation between NOD2 and TLR4 genotype and earlier onset of disease. This was also true for homozygotes and compound heterozygotes. In fact, we found that there was a trend to later onset disease with more of the classical (R702W, G908R, and fs1007) NOD2/CARD15 mutated alleles (Fig. 2), although this did not reach statistical significance, possibly because of our sample size. JW1 was unrelated to age. We surmise that the differences noted in our study are due to the inclusion of a pediatric cohort and use of single-family members, although differences in ethnicity might also influence AOO. Jewish Ashkenazi ethnicity seems to cause younger onset in male individuals irrespective of NOD2/ CARD15. Carriage of fs 1007 in our population was uncommon, and homozygotes for fs 1007 or R702W were exceedingly rare in our population. This has also been noted in previous studies from Israel from our group and others $(31,34,35)$, so in any case, these mutations or double-dose NOD2/CARD15 mutations do not explain early $\mathrm{AOO}$ in the vast majority of cases in our population.

Presence or absence of the background polymorphism P268S was found to be correlated with onset of disease. Absence of a mutation was significantly associated with decreasing age of $\mathrm{CD}$ onset. Although this could be perceived to be a protective effect of the mutation, this concept seems 


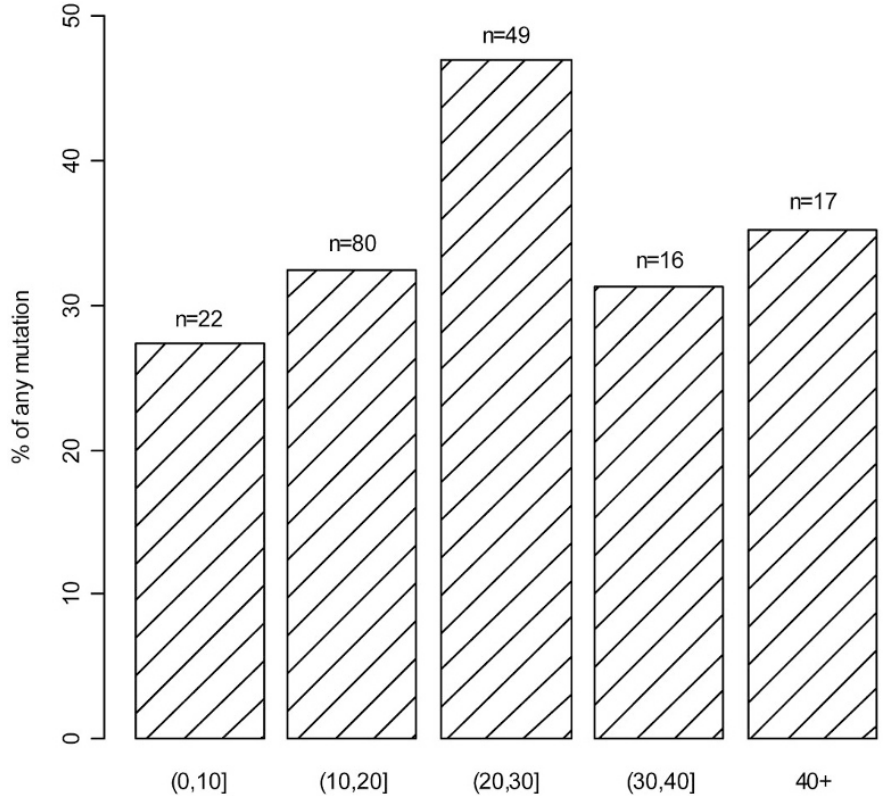

Figure 2. Frequency of any NOD2/CARD15 mutation (SNPs 8, 12, and 13) by AOO (portrayed by decades).

unlikely given that this mutation has not been shown to alter NOD2 function. A more plausible explanation is related to the presence of linkage disequilibrium between $\mathrm{P} 268 \mathrm{~S}$ and mutations in NOD2/CARD15. All of the previously described disease-associated mutations and haplotypes occur on a common background that contains P268S $(8,16,19,20)$. Thus, P268S to date seems to function as a marker for mutations in the NOD2/CARD15 gene and possibly the IBDI locus. This finding is consistent with the findings of Sugimura et al. (19) and Tukel et al. (20), who used variant P268S as a marker for unknown mutations.

Because the well-recognized mutations do not account for all of the linkage between this site and CD $(19-21,30)$, other as-yet-unidentified mutations in this region in linkage with P268S may be responsible for disease in adults. Conversely, the lower prevalence of P268S in the juvenile-onset cohort without recognized NOD2/CARD15 mutations may indicate that mutations on the IBDI locus in or outside the NOD2/ CARD15 gene or genes from other loci could be primarily responsible for pediatric onset of $\mathrm{CD}$. This hypothesis was reinforced further by haplotype analysis in patients with or without recognized NOD2/CARD15 mutations. We found that P268S mutations were associated with increasing age and adult-onset disease primarily in patients without other mutations in NOD2/CARD15, whereas absence of P268S was correlated with pediatric onset in patients without other mutations in NOD2/CARD15. The JW1 haplotype was not responsible for this difference, because haplotypes with P268S but without JW1 showed an even stronger association with increasing age. We did not perform NOD2 and TLR4 analysis in a control population in this study because these have been performed by our centers on 159 healthy control subjects (31) and previously published (36) and are not relevant to AOO in established disease.
Finally, the significantly higher percentage of male individuals with juvenile onset may also raise the possibility that a gender-specific locus may lead to altered AOO. Fisher et al. (37) reported that gender-specific linkage for male disease was present for the major histocompatibility region on chromosome $6 p$, a region referred to as the IBD3 Locus. Gender linkage was not found for disease related to the IBD1 locus carrying NOD2/CARD15.

In conclusion, the common disease-associated mutations in the NOD2/CARD15 and TLR4 genes, homozygosity, and compound heterozygosity do not seem to play a role in AOO of disease in our population. Haplotypes without these mutations are associated with $\mathrm{AOO}$ of disease. Haplotypes in linkage disequilibrium with the $\mathrm{P} 268 \mathrm{~S}$ polymorphism in the NOD2/CARD15 gene seem to be associated with increasing age and adult-onset disease. Conversely, predominantly male gender in the juvenile group and absence of the P268S background polymorphism might indicate that mutations located outside NOD2/CARD15 may play a more significant role in juvenile- or pediatric-onset disease.

\section{REFERENCES}

1. Hugot JP, Zouali H, Lesage S, Thomas G 1999 Etiology of the inflammatory bowel diseases. Int J Colorec Dis 14:2-9

2. Fiocchi C 1998 Inflammatory bowel disease: etiology and pathogenesis. Gastroenterology 115:182-205

3. Thompson NP, Driscoll R, Pounder RE, Wakefield AJ 1996 Genetics versus environment in inflammatory bowel disease; results of a British twin study. BMJ 312:95-96

4. Sartor RB 1997 Pathogenesis and immune mechanisms of chronic inflammatory bowel diseases. Am J Gastroenterol 92:5S-11S

5. Sentongo TA, Semeao EJ, Piccoli DA, Stallings VA, Zemel BS 2000 Growth, body composition, and nutritional status in children and adolescents with Crohn's disease. J Pediatr Gastroenterol Nutr 31:33-40

6. Mamula P, Telega GW, Markowitz JE, Brown KA, Russo PA, Piccoli DA, Baldassano RN 2002 Inflammatory bowel disease in children 5 years of age and younger. Am J Gastroenterol 97:2005-2010

7. Card T, Hubbard R, Logan RF 2003 Mortality in inflammatory bowel disease: a population-based cohort study. Gastroenterology 125:1583-1590

8. Hugot JP, Chamaillard M, Zouali H, Lesage S, Cezard JP, Belaiche J, Almer S, Tysk C, O'Morain CA, Gassull M, Binder V, Finkel Y, Cortot A, Modigliani R, LaurentPuig P, Gower-Rousseau C, Macry J, Colombel JF, Sahbatou M, Thomas G 2001 Association of NOD2 leucine-rich repeat variants with susceptibility to Crohn's disease. Nature 411:599-603

9. Ogura Y, Bonen DK, Inohara N, Nicolae DL, Chen FF, Ramos R, Britton H, Moran T, Karaliuskas R, Duerr RH, Achkar JP, Brant SR, Bayless TM, Kirschner BS, Hanauer SB, Nunez G, Cho JH 2001 A frameshift mutation in NOD2 associated with susceptibility to Crohn's disease. Nature 411:603-606

10. Hampe J, Cuthbert A, Croucher PJ, Mirza MM, Mascheretti S, Fisher S, Frenzel H, King K, Hasselmeyer A, MacPherson AJ, Bridger S, van Deventer S, Forbes A, Nikolaus S, Lennard-Jones JE, Foelsch UR, Krawczak M, Lewis C, Schreiber S, Mathew CG 2001 Association between insertion mutation in NOD2 gene and Crohn's disease in German and British populations. Lancet 357:1925-1928

11. Inohara N, Nunez G 2001 The NOD: a signaling module that regulates apoptosis and host defense against pathogens. Oncogene 20:6473-6481

12. Girardin SE, Boneca IG, Viala J, Chamaillard M, Labigne A, Thomas G, Philpott DJ, Sansonetti PJ 2003 NOD2 is a general sensor of peptidoglycan through muramyl dipeptide (MDP) detection. J Biol Chem 278:8869-8872

13. Inohara N, Ogura Y, Fontalba A, Gutierrez O, Pons F, Crespo J, Fukase K, Inamura S, Kusumoto S, Hashimoto M, Foster SJ, Moran AP, Fernandez-Luna JL, Nunez G 2003 Host recognition of bacterial muramyl dipeptide mediated through NOD2. Implications for Crohn's disease. J Biol Chem 278:5509-5512

14. Ogura Y, Inohara N, Benito A, Chen FF, Yamaoka S, Nunez G 2001 Nod2, a Nod1/Apaf-1 family member that is restricted to monocytes and activates NF- $\kappa \mathrm{B}$. J Biol Chem 276:4812-4818

15. Bonen DK, Ogura Y, Nicolae DL, Inohara N, Saab L, Tanabe T, Chen FF, Foster SJ, Duerr RH, Brant SR, Cho JH, Nunez G 2003 Crohn's disease-associated NOD2 variants share a signalling defect in response to lipopolysaccharide and peptidoglycan. Gastroenterology 124:140-146

16. Lesage S, Zouali H, Cezard JP, Colombel JF, Belaiche J, Almer S, Tysk C, O’Morain C, Gassull M, Binder V, Finkel Y, Modigliani R, Gower-Rousseau C, Macry J, Merlin F, Chamaillard M, Jannot AS, Thomas G, Hugot JP; EPWG-IBD Group; EPIMAD Group; GETAID Group 2002 CARD15/NOD2 mutational analysis and 
genotype-phenotype correlation in 612 patients with inflammatory bowel disease Am J Hum Genet 70:845-857

17. Ahmad T, Armuzzi A, Bunce M, Mulcahy-Hawes K, Marshall SE, Orchard TR, Crawshaw J, Large O, de Silva A, Cook JT, Barnardo M, Cullen S, Welsh KI, Jewell DP 2002 The molecular classification of the clinical manifestations of Crohn's disease. Gastroenterology 122:854-866

18. Cuthbert AP, Fisher SA, Mirza MM, King K, Hampe J, Croucher PJ, Mascheretti S, Sanderson J, Forbes A, Mansfield J, Schreiber S, Lewis CM, Mathew CG 2002 The contribution of NOD2 gene mutations to the risk and site of disease in inflammatory bowel disease. Gastroenterology 122:867-874

19. Sugimura K, Taylor KD, Lin YC, Hang T, Wang D, Tang YM, Fischel-Ghodsian N, Targan SR, Rotter JI, Yang H 2003 A novel NOD2/CARD15 haplotype conferring risk for Crohn disease in Ashkenazi Jews. Am J Hum Genet 72:509-518

20. Tukel T, Shalata A, Present D, Rachmilewitz D, Mayer L, Grant D, Risch N, Desnick RJ 2004 Crohn disease: frequency and nature of CARD15 mutations in Ashkenaz and Sephardi/Oriental Jewish families. Am J Hum Genet 74:623-636

21. Bonen D, Cho J 2003 The genetics of Inflammatory bowel disease. Gastroenterology 124:521-536

22. Brant SR, Picco MF, Achkar JP, Bayless TM, Kane SV, Brzezinski A, Nouvet FJ, Bonen D, Karban A, Dassopoulos T, Karaliukas R, Beaty TH, Hanauer SB, Duerr RH, Cho JH 2003 Defining complex contributions of NOD2/CARD15 gene mutations, age at onset, and tobacco use on Crohn's disease phenotypes. Inflamm Bowel Dis 9:281-289

23. Aderem A, Ulevitch RJ 2000 Toll-like receptors in the induction of the innate immune response. Nature 406:782-787

24. Agnese DM, Calvano JE, Hahm SJ, Coyle SM, Corbett SA, Calvano SE, Lowry SF 2002 Human toll-like receptor 4 mutations but not CD14 polymorphisms are associated with an increased risk of gram-negative infections. J Infect Dis 186:1522-1525

25. Cario E, Podolsky DK 2000 Differential alteration in intestinal epithelial cell expression of toll-like receptor 3 (TLR3) and TLR4 in inflammatory bowel disease. Infect Immun 68:7010-7017

26. Arbour NC, Lorenz E, Schutte BC, Zabner J, Kline JN, Jones M, Frees K, Watt JL, Schwartz DA 2000 TLR4 mutations are associated with endotoxin hyporesponsiveness in humans. Nat Genet 25:187-191

27. Erridge C, Stewart J, Poxton IR 2003 Monocytes heterozygous for the Asp299Gly and Thr399Ile mutations in the Toll-like receptor 4 gene show no deficit in lipopolysaccharide signaling. J Exp Med 197:1787-1791
28. Poltorak A, He X, Smirnova I, Liu MY, Van Huffel C, Du X, Birdwell D, Alejos E, Silva M, Galanos C, Freudenberg M, Ricciardi-Castagnoli P, Layton B, Beutler B 1998 Defective LPS signalling in C3H/HeJ and C57BL/10ScCr mice: mutations in Tlr4 gene. Science 282:2085-2088

29. Elson CO, Cong Y, Sundberg J 2000 The C3H/HeJBIR mouse model: a high susceptibility phenotype for colitis. Int Rev Immunol 19:63-75

30. Franchimont D, Vermeire S, El Housni H, Pierik M, Van Steen K, Gustot T, Quertinmont E, Abramowicz M, Van Gossum A, Deviere J, Rutgeerts P 2004 Deficient host-bacteria interactions in inflammatory bowel disease: the toll-like receptor(TLR)-4 Asp299gly polymorphism is associated with Crohn's disease and ulcerative colitis. Gut 53:987-992

31. Karban A, Waterman M, Panhuysen CI, Pollak RD, Nesher S, Datta L, Weiss B, Suissa A, Shamir R, Brant SR, Eliakim R 2004 NOD2/CARD15 genotype and phenotype differences between Ashkenazi and Sephardic Jews with Crohn's disease. Am J Gastroenterol 99:1134-1140

32. Ahmadian A, Gharizadeh B, Gustafsson AC, Sterky F, Nyren P, Uhlen M, Lundeberg J 2000 Single nucleotide polymorphism analysis by pyrosequencing. Anal Biochem 280:103-110

33. Lorenz E, Frees KL, Schwartz DA 2001 Determination of the TLR4 genotype using allele-specific PCR. Biotechniques 31:22-24

34. Fidder HH, Olschwang S, Avidan B, Zouali H, Lang A, Bardan E, Picard O, Bar-Meir S, Colombel JF, Chowers Y 2003 Association between mutations in the CARD15 (NOD2) gene and Crohn's disease in Israeli Jewish patients. Am J Med Genet A 121:240-244

35. Fidder HH, Avidan B, Lahav M, Bar-Meir S, Chowers Y 2003 Clinical and demographic characterization of Jewish Crohn's disease patients in Israel. J Clin Gastroenterol 36:8-12

36. Tal G, Mandelberg A, Dalal I, Cesar K, Somekh E, Tal A, Oron A, Itskovich S, Ballin A, Houri S, Beigelman A, Lider O, Rechavi G, Amariglio N 2004 Association between common Toll-like receptor 4 mutations and severe respiratory syncytial virus disease. J Infect Dis 189:2057-2063

37. Fisher SA, Hampe J, Macpherson AJ, Forbes A, Lennard-Jones JE, Schreiber S, Curran ME, Mathew CG, Lewis CM 2002 Sex stratification of an inflammatory bowel disease genome search shows male-specific linkage to the HLA region of chromosome 6. Eur J Hum Genet 10:259-265 